\title{
Determination of reaction orders for ascorbic acid degradation during sterilization using a new experimental device: The thermoresistometer Mastia ${ }^{\circledR}$
}

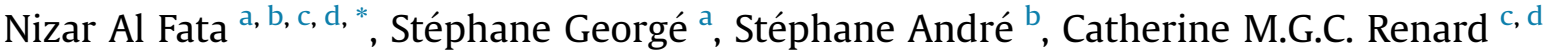 \\ ${ }^{a}$ CTCPA, unité qualité nutritionnelle, Site Agroparc, 449 Clément Ader, BP 21203, 84911 Avignon Cedex 9, France \\ ${ }^{\mathrm{b}}$ CTCPA, unité de microbiologie EMaiRIT'S, Site Agroparc, 449 Clément Ader, BP 21203, 84911 Avignon Cedex 9, France \\ ' INRA, UMR408 Sécurité et Qualité des Produits d'Origine Végétale, Domaine Saint Paul, Site Agroparc, F-84000 Avignon, France \\ d Avignon University, UMR408 Sécurité et Qualité des Produits d'Origine Végétale, Domaine Saint Paul, Site Agroparc, F-84000 Avignon, France
}

Keywords:

Vitamin C

Canning

Modelling

Kinetics

Nutritional qualities

\section{A B S T R A C T}

Sterilization is the most relevant technique to guaranty safety of shelf-stable highly hydrated food products at ambient temperature. However, these thermal processes are often optimised to microbiological aspect and consequently are not without consequences on food quality. Ascorbic acid's degradation at sterilization temperature $\left(>100^{\circ} \mathrm{C}\right)$ is poorly documented. Using a new instrumented reactor (thermoresistometer Mastia ${ }^{\circledR}$ ), the behavior of ascorbic acid was studied in food model solution at $\mathrm{pH}=3.5$, in aerobic and anaerobic conditions from $95^{\circ} \mathrm{C}$ to $125^{\circ} \mathrm{C}$. In anaerobic conditions, degradation was slow and followed first order kinetics $\left(k_{125^{\circ} \mathrm{C}}=2.88^{*} 10^{-3} \mathrm{~min}^{-1}, E_{a}=96 \mathrm{~kJ} / \mathrm{mol}\right)$. In aerobic conditions, reactions were faster with total elimination of ascorbic acid in about $4 \mathrm{~h}$, and the data were best fitted using 0.5-order, while reaction speed varied little with temperature.

\section{Introduction}

Ascorbic acid is often used as an indicator molecule in food processing because it is highly reactive and very sensitive to physico-chemical conditions in the medium. Indeed, ascorbic acid degradation is influenced by the presence of oxygen, temperature (Lin \& Agalloco, 1979; Torregrosa, Esteve, Frígola, \& Cortés, 2006), light intensity (Bosch et al., 2013; Sapei \& Hwa, 2014), pH, water activity (Berlinet, Brat, Brillouet, \& Ducruet, 2006; Mercali, Jaeschke, Tessaro, \& Marczak, 2012), ${ }^{\circ}$ Brix (Al-Zubaidy \& Khalil, 2007), the presence of metallic ions such as $\mathrm{Fe}^{2+}$ or $\mathrm{Cu}^{2+}$ (Bosch et al., 2013; Lin \& Agalloco, 1979; Soares \& Hotchkiss, 1999), presence of sugars (Hsu, Tsai, Fu, \& Wu, 2012), amino acids, sugars, lipids and enzymes (Mercali, Schwartz, Marczak, Tessaro, \& Sastry, 2014), or microorganisms (Soares \& Hotchkiss, 1999). Storage conditions (packaging, temperatures of storage, etc ...) also have an

* Corresponding author. CTCPA, unité qualité nutritionnelle, Site Agroparc, 449 Clément Ader, BP 21203, 84911 Avignon Cedex 9, France.

E-mail addresses: nalfata@ctcpa.org (N. Al Fata), sgeorge@ctcpa.org (S. Georgé), sandre@ctcpa.org (S. André), catherine.renard@avignon.inra.fr (C.M.G.C. Renard). effect on the shelf-life of ascorbic acid (Mercali et al., 2012; Torregrosa et al., 2006).

Thermal treatment is the most popular and efficient method to inactivate microorganisms to stabilize canned vegetables (Blasco, Esteve, Frígola, \& Rodrigo, 2004; Peng et al., 2012; Zimmermann, Longhi, Schaffner, \& Aragão, 2014). There is an increased demand of nutritive foods, thereby, there were many attempts to maximise nutrients retention during industrial processes as well as during transport and storage (Sapei \& Hwa, 2014). To be efficient, a thermal treatment must ensure that the product has been exposed at sufficiently high temperature for a sufficient time to destroy an appropriate number of targeted microorganisms (Zimmermann et al., 2014). Nevertheless, thermal treatments can generate undesirable chemical reactions like vitamin degradation, which can lead to products having less nutritive interest. In the literature, only few studies are focussed on the degradation of ascorbic acid at sterilization temperature (Blasco et al., 2004; Esteve, Frígola, Martorell, \& Rodrigo, 1998; Oey, Verlinde, Hendrickx, \& Van Loey, 2006; Van den Broeck, Ludikhuyze, Weemaes, Van Loey, \& Hendrickx, 1998). It is generally assumed that the degradation of ascorbic acid follows first-order kinetics in food systems (Jiang, Zheng, \& Lu, 2014), but it can follow second-order kinetics if oxygen is present in a limited 
amount in the media (Lin \& Agalloco, 1979). Ascorbic acid degradation at sterilization temperatures is poorly known, probably because of the difficulty to work at above $100{ }^{\circ} \mathrm{C}$ (Blasco et al., 2004; Esteve et al., 1998; Oey et al., 2006; Van den Broeck et al., 1998). First order kinetics were reported by Van den Broeck et al. (1998) in orange and tomato juices in anaerobic conditions between 120 and $150{ }^{\circ} \mathrm{C}$, by Esteve et al. (1998) in green asparagus extracts both in aerobic and anaerobic conditions between 110 and $140{ }^{\circ} \mathrm{C}$, and by Blasco et al. (2004) in mushroom extracts both in aerobic and anaerobic conditions between 110 and $140{ }^{\circ} \mathrm{C}$. In the last two cases, degradation was faster under aerobic condition than under anaerobic conditions. Oey et al. (2006) state that ascorbic acid degradation follows first order kinetics in a case where oxygen is limited between 110 and $120{ }^{\circ} \mathrm{C}$. However they report ascorbic acid degradation profiles which display two steps: a first, very rapid step, corresponding to the aerobic pathway where dissolved oxygen is involved, and a second, slower step when oxygen has been consumed and the anaerobic pathway occurs.

Our goal was to study the degradation of ascorbic acid depending on two factors, the availability of oxygen and temperature, in conditions relevant for the canning industry (temperature $>100{ }^{\circ} \mathrm{C}$, pressure $>0.1 \mathrm{MPa}$ ). The thermoresistometer Mastia ${ }^{\circledR}$ is used in microbiology in order to determine the heat resistances of microorganisms, both in model solution and in various matrices, during isothermal or non-isothermal treatments and for more than 20 years (Condón, Arrizubieta, \& Sala, 1993; Garza, Teixidó, Sanchis, Viñas, \& Condón, 1994; Palop, Marco, Raso, Sala, \& Condón, 1997; Palop, Raso, Pagàn, Condón, \& Sala, 1999; Palop, Sala, \& Condón, 1997; Raso, Palop, Bayarte, Condón, \& Sala, 1995). The accuracy of the thermoresistometer allows determining $D$-values close to $10^{-3} \min$ (Condón et al., 1993), especially due to its fast homogenization. It works at temperature higher than $100{ }^{\circ} \mathrm{C}$, under high pressure and at modified gas composition and therefore was appropriate to our goal.

\section{Materials \& methods}

\subsection{Reagents}

All the reagents used were purchased from Fisher Chemical (Illkirch, France) and are analytical grade or better.

\subsection{Preparation of ascorbic acid solution}

A $5.0000 \mathrm{~g}$ accurately weighed portion of L-ascorbic acid was dissolved in $25 \mathrm{~mL}$ of $23.1 \mathrm{~mL} / \mathrm{L}$ acetic acid solution $(\mathrm{pH}=2.6)$ in a $25 \mathrm{~mL}$ volumetric flask. The mixture was then stirred until complete dissolution of ascorbic acid. A volume of $1.8 \mathrm{~mL}$ of this solution was injected inside the vessel of the thermoresistometer, in order to have an initial concentration of ascorbic acid in the heating media at $90 \mathrm{mg} / 100 \mathrm{~mL}$.

\subsection{Model solution}

Citrate-phosphate Mcllvaine buffer $(\mathrm{pH}=3.5)$ was used as heating medium. Mcllvaine buffer was prepared using a $0.1 \mathrm{~mol} / \mathrm{L}$ monohydrate citric acid solution and a $0.2 \mathrm{~mol} / \mathrm{L}$ disodium phosphate solution (McIlvaine, 1921). The buffer was stored at $4{ }^{\circ} \mathrm{C}$ until used.

\subsection{High-performance liquid chromatography}

Analysis of ascorbic acid was carried out using a 1260 Agilent infinity LC chromatograph with a 1290 Agilent diode-array detector. A $150 \times 3.0 \mathrm{~mm}$ Synergi Polar RP-C18 column (Phenomenex) was used with a precolumn and both have a particle size of $4 \mu \mathrm{m}$. The mobile phase was a $23.1 \mathrm{~mL} / \mathrm{L}$ acetic acid solution as eluent $\mathrm{A}$ and acetonitrile as eluent $B$. The flow rate was fixed at $0.8 \mathrm{~mL} \mathrm{~min}^{-1}$, the column temperature was set at $30^{\circ} \mathrm{C}$ and the injection volume was $5 \mu \mathrm{L}$. A gradient program was performed as follows: the initial conditions were $96 \%$ A/4\% B; 0-5 min, 96\% A/4\% B; 5-10 min, 80\% $\mathrm{A} / 20 \% \mathrm{~B} ; 10-15 \mathrm{~min}, 96 \% \mathrm{~A} / 4 \% \mathrm{~B}$. The data acquisition was assessed at $245 \mathrm{~nm}$, corresponding to the maximum absorbance of ascorbic acid in UV-visible spectrometry (Jaffe, 1984). Quantification of ascorbic acid was carried out by external standard method with a calibration curve, which is the mean of five calibration curves established by five standard solutions of ascorbic acid injected in HPLC in the same conditions.

\subsection{Determination of heat resistance by the thermoresistometer Mastia $^{\circledR}$}

Thermal treatments were carried out in a thermoresistometer TR-SC Mastia ${ }^{\circledR}$ (Fig. 1), the operation system of which is described by Conesa et al. (Conesa, Andreu, Fernández, Esnoz, \& Palop, 2009). It works in a temperature range from $20^{\circ} \mathrm{C}$ to $150{ }^{\circ} \mathrm{C}$ under pressure, using different gases like air or nitrogen, having a constant and regulated stirring, sampling or injecting at any time during the heat treatment, even under pressure, without perturbation of the experimental media, working at large volumes (maximum $400 \mathrm{~mL}$ ), and simulating isothermal and non-isothermal heat treatments.

The thermoresistometer TR-SC possesses a $2 \mathrm{~kW}$ heating electric element (2) and a cooling ring (1) in which cold water $\left(2^{\circ} \mathrm{C}\right)$ provided by the cooling system (A) is circulating. This device is implemented with a programmable logic control (PLC) (B), which powers the heating electric element and the cooling system. The programmable logic control is connected to a tactile screen (C) for communication with to the PLC, and a computer (D) provided with a software able to program or/and register temperature profiles (Conesa et al., 2009). The working media is put in a classical stainless vessel or a teflonated stainless vessel $(8.5 \times 12 \mathrm{~cm}$ outer diameter) respectively for microbiological or chemical studies (E), which is screwed on the thermoresistometer cap with an O-ring $(F)$. This cap has a stirring shaft with a propeller (3) which is powered by the stirring motor (I), and eight ports with screw cap; one is holding the pressure source $(G)$, another is the injection port and

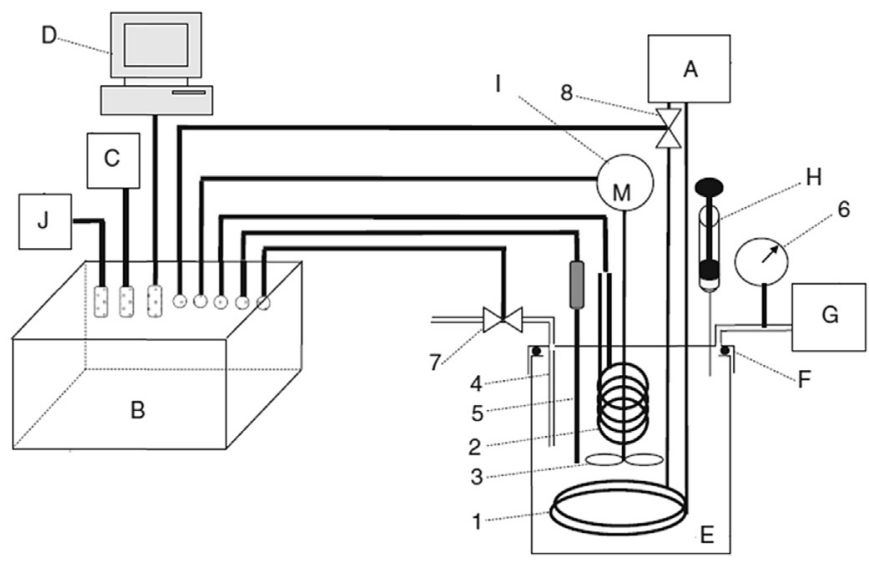

Fig. 1. Diagram of the Thermoresistometer Mastia ${ }^{\circledR}$ set up. (A) Cooling water. (B) Programmable Logic Controller (PLC). (C) Tactile screen. (D) Computer. (E) Vessel. (F) Cap. (G) Pressure source (air or $\mathrm{N}_{2}$ ). (H) Hamilton-type syringe. (I) Stirring motor. (J) Proportional Integral Derivative (PID). (1) Cooling ring. (2) Electric heating element. (3) Propeller. (4) Sampling tube. (5) Thermocouple. (6) Manometer. (7) Solenoid sampling valve. (8) Solenoid valve for the coiling system redrawn from Conesa et al. (2009). 
contain a gas chromatography septum, a third one holds the sampling tube (4), another holds the thermocouple (5), two ports maintain the electric element and two others maintain the cooling ring.

The vessel can be pressurized by a manometer (6) connected to the pressure source $(G)$. Pressurization is needed to allow extraction of samples and to avoid boiling at temperatures higher than $100{ }^{\circ} \mathrm{C}$ in aqueous solutions. A specific Hamilton-type syringe $(\mathrm{H})$ was used to injected samples in the vessel in order to overcome the pressure.

For all experiments, the over pressure of the vessel was set at $0.2 \mathrm{MPa}$, i.e a total pressure of $0.3 \mathrm{MPa}$. The temperature range studied is from $95{ }^{\circ} \mathrm{C}$ to $125^{\circ} \mathrm{C}$. Aerobic conditions were obtained using air as headspace gas. Anaerobic conditions were performed by removal of oxygen from the media by heating to $95{ }^{\circ} \mathrm{C}$ during $30 \mathrm{~min}$ and bubbling nitrogen in situ during $30 \mathrm{~min}$ at $20{ }^{\circ} \mathrm{C}$ through the sampling tube, and then using nitrogen as headspace gas. Establishment of anaerobic conditions was validated by measuring oxygen concentration after each step using a PreSens Fibox 4 device (Regensburg, Germany) coupled to a fiber optic probe with a sensor type PSt3 (limit of detection $30 \mathrm{~Pa}$ oxygen, $0.015 \mathrm{mg} / \mathrm{L}$ dissolved oxygen). Each thermal treatment lasted $320 \mathrm{~min}$.

\subsection{Kinetic models}

Generally, it is assumed that ascorbic acid (AA) degradation can follow two pathways: one is the oxidoreductive (aerobic) pathway by the formation of dehydroascorbic acid (DHAA), and another is by hydrolytic (anaerobic) pathway, by direct cleavage of the lactone ring of ascorbic acid molecule (Yuan \& Chen, 1998). The principal characteristics of these two mechanisms are rapidly described as follow:

\subsubsection{Oxidoreductive mechanism}

\section{$\mathrm{AA} \rightleftarrows \mathrm{DHAA} \rightarrow 3-\mathrm{DKG}$}

The formation of DHAA from AA is reversible depending on redox potential. It is assumed that the reformation of $A A$ from DHAA is negligible unless the medium is specifically made reductive, and this is more true at high temperature (Serpen \& Gökmen, 2007). DHAA is then irreversibly degraded to 3-diketogulonic acid.

\subsubsection{Anaerobic pathway}

This degradation pathway is akin to sugar degradation and does not require oxygen.

The global ascorbic acid degradation taking in account both mechanisms can be described by the following differential equation:

$\frac{\mathrm{d}[A A]}{\mathrm{d} t}=-k_{0 x} \cdot[A A]^{\alpha}\left[O_{2}\right]^{\beta}-k_{H} \cdot[A A]^{\gamma}$

where $[A A]$ is the ascorbic acid concentration, $\left[\mathrm{O}_{2}\right]$ the dissolved oxygen concentration, $k_{o x}$ and $k_{H}$ are the kinetic constants respectively for aerobic and anaerobic degradation, $\alpha$ is the partial kinetic order regarding ascorbic acid concentration for aerobic degradation, $\beta$ the partial kinetic order regarding dissolved oxygen concentration and $\gamma$ the partial order regarding ascorbic acid concentration for aerobic degradation.

In anaerobic conditions with $\left[\mathrm{O}_{2}\right]=0$, equation (1) can be simplified to:
$\frac{\mathrm{d}[A A]}{\mathrm{d} t}=-k_{H} \cdot[A A]^{\gamma}$

Ascorbic acid degradation in anaerobic or aerobic conditions was fitted by using general $n$-order kinetics model in order to determine the partial reaction order parameter $\alpha$ or $\gamma$ :

$\mathrm{n}$ - order kinetics : $C_{t}=\left(C_{0}^{1-n}+(n-1) \cdot k(T) \cdot t\right)^{\frac{1}{1-n}}$

Starting from equation (3), we linearized the equation in order to obtain a straight line curve as described by the following equation:

$C_{t}^{1-n}=C_{0}^{1-n}+(n-1) \cdot k \cdot t$

where $(n-1) \cdot k$ is the slop of the curve and $C_{0}^{1-n}$ is the intercept.

The kinetic constant $k$ is then determined by taking the inverse of the slop of the curve described by equation (4).

From these results, 0.5 -order kinetics and first-order kinetics models were again used to model ascorbic acid degradation:

0.5 - order kinetics : $C_{t}=C_{0}-k(T) \cdot t \cdot \sqrt{C_{0}}+\frac{(k(T) \cdot t)^{2}}{4}$

first - order kinetics : $C_{t}=C_{0} \cdot \exp (-k(T) \cdot t)$

where $C_{t}$ is the ascorbic acid concentration at time $t, C_{0}$ is the initial ascorbic acid concentration, $k$ is the rate constant and $n$ is the partial reaction order of ascorbic acid, $T$ is the temperature and $t$ is the time in minute.

The temperature dependence of $k$ was fitted using Arrhenius law:

$k(T)=A \cdot \exp \left(\frac{-E_{a}}{R T}\right)$

where $A$ is the frequency factor (also called pre-exponential factor), $E_{a}$ is the activation energy, and $R$ is the ideal gas constant.

\subsection{Analysis of data}

All experiments were repeated at least two times and each point was sampled twice; the results were reported as average.

\subsection{Statistical analysis}

To evaluate the fit of a model fit to the data, we analysed residual plots between the data and the model. Shapiro-Wilk test was used to determine if residues were normally distributed or not at a chosen alpha level of 0.05 . The p-value was analysed to discriminate if the distribution is normal or not. When the p-value was superior to the $\alpha$-level, we considered that the residues are normally distributed.

\section{Results \& discussion}

\subsection{Anaerobic conditions}

In anaerobic conditions (Fig. 2) not all the ascorbic acid was degraded even after $320 \mathrm{~min}$ and regardless of the temperature. Moreover, after $320 \mathrm{~min}$, degradation of ascorbic acid was only about $8 \%$ at $95{ }^{\circ} \mathrm{C}$, around $18 \%$ at $105{ }^{\circ} \mathrm{C}$, around $36 \%$ at $115^{\circ} \mathrm{C}$ and a maximum of degradation around $61 \%$ at $125{ }^{\circ} \mathrm{C}$. Fitting all curves simultaneously gave a reaction order $n=0.83$. As analysed by Van 


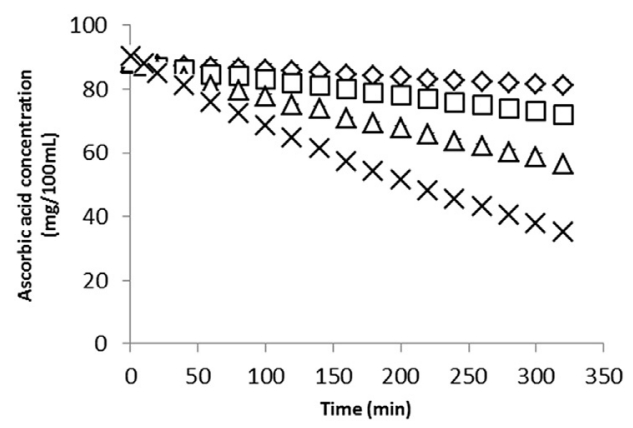

Fig. 2. Ascorbic acid degradation in anaerobic conditions at $95{ }^{\circ} \mathrm{C}(\diamond), 105{ }^{\circ} \mathrm{C}(\square)$, $115^{\circ} \mathrm{C}(\Delta)$ and $125^{\circ} \mathrm{C}(\mathrm{x})$ in Mcllvaine buffer $\mathrm{pH}=3.5$.

Boeckel, no real distinction can be made between models if the fractional conversion is less than 60-70\% (Van Boekel, 2009). Indeed, we can legitimately base the determination of order reaction only on the degradation curve at $125^{\circ} \mathrm{C}$, with a degradation of $61 \%$, whereas it is less than $20 \%$ at the other temperatures. The reaction order determined at $125{ }^{\circ} \mathrm{C}$ was $n=0.84$. We chose thereby to use first-order kinetics to fit the data. The $R^{2}$ was compared for $n=0.84$ and $n=1$ in order to confirm that there is no significant difference between the calculated value of $n$ and the fit of $n=1$. A good fit was obtained for all four temperatures using $n=1\left(\mathrm{R}^{2}>0.99\right)$ and the $R^{2}$ was the same for the two different $n$ values (Table 1 ). The residues were randomly dispersed in the residual plot between the data and the obtained values with firstorder kinetics model at $125{ }^{\circ} \mathrm{C}$, and the p-value was 0.91 at an $\alpha$ level of 0.05 , i.e the residues are normally distributed.

The values of first-order kinetic constants are reported in Table 1 . The $k_{H}$-values obtained are lower than those obtained by Van den Broeck et al. (1998), Blasco et al. (2004), Esteve et al. (1998) and Oey et al. (2006), probably due to the fact that in our case the anaerobic conditions were strict (the heating media was deaerated before each experiment and nitrogen was used as headspace gas), while in their cases, no deareation is mentioned before heating treatment and therefore a certain amount of oxygen was present in the treated media.

There was a clear impact of temperature and the kinetic constants were used to calculate Arrhenius parameters (Fig. 3). The activation energy determined had a value of $96 \mathrm{~kJ} / \mathrm{mol}$. This value is of the same order of magnitude though slightly lower than those reported for ascorbic acid degradation in plant foods at canning temperature: under anaerobic conditions, Van den Broeck et al. (1998) have determined activation energies of $117 \mathrm{~kJ} / \mathrm{mol}$ and $105 \mathrm{~kJ} / \mathrm{mol}$ respectively for ascorbic degradation in orange juice and tomato juice between $120^{\circ} \mathrm{C}$ and $150{ }^{\circ} \mathrm{C}$, Esteve et al. (1998) have determined an activation energy of $140 \mathrm{~kJ} / \mathrm{mol}$ for ascorbic acid degradation in green asparagus.

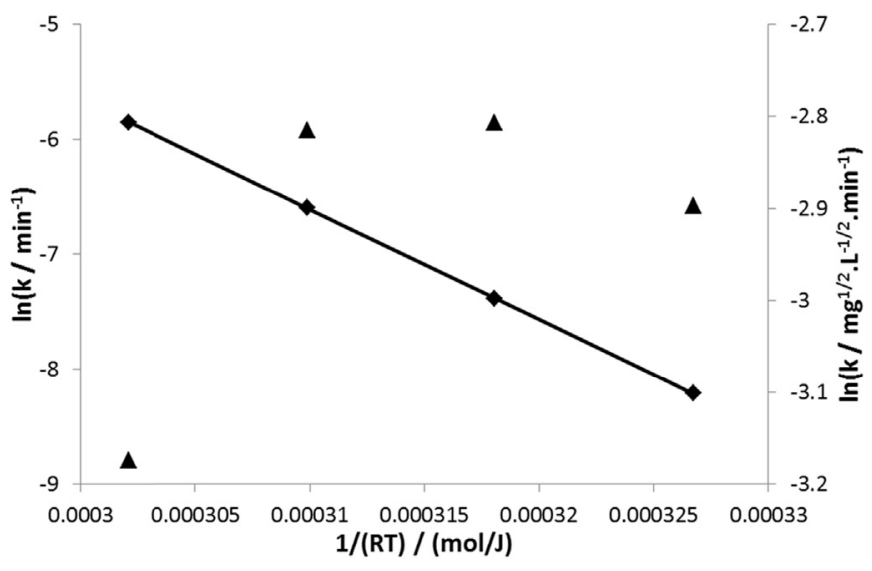

Fig. 3. Effect of temperature on the rate constant of ascorbic acid degradation in anaerobic conditions (filled square) referred to the left axis and in aerobic conditions (filled triangle) referred to the right axis.

\subsection{Aerobic conditions}

In presence of air, ascorbic acid had totally disappeared after 240 min at 95,105 and $115{ }^{\circ} \mathrm{C}$. All four temperatures gave almost identical degradation curves, except that at $125{ }^{\circ} \mathrm{C}$ which had a slight tail (Fig. 4). In aerobic conditions, the temperature has a limited effect on the ascorbic acid degradation in this range. In fact, the degradation curves were superimposed regardless of temperature. We assumed that the degradation observed was due to both the anaerobic mechanism described above and an aerobic component connected with $\mathrm{O}_{2}$ presence.

Three points called for attention:

A first point was that ascorbic acid degradation was enhanced in the presence of air instead of nitrogen in the same system: even at

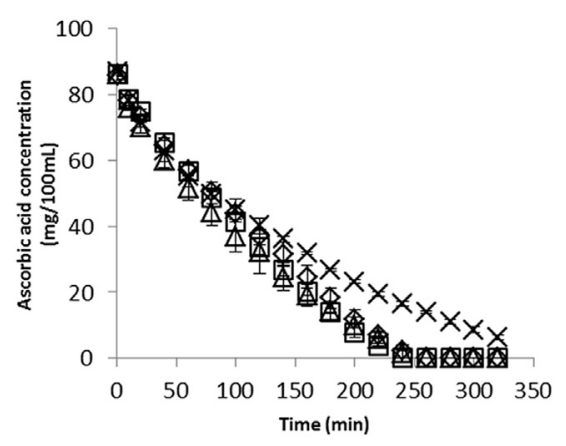

Fig. 4. Ascorbic acid degradation in aerobic conditions at $95^{\circ} \mathrm{C}(\diamond), 105^{\circ} \mathrm{C}(\square), 115^{\circ} \mathrm{C}$ $(\Delta)$ and $125^{\circ} \mathrm{C}(\mathrm{x})$ in Mcllvaine buffer $\mathrm{pH}=3.5$.

Table 1

Kinetic constant as function of temperature for ascorbic acid degradation in anaerobic conditions (first-order in $\left.10^{-4 *} \min ^{-1}\right)$ and in aerobic conditions $\left(0.5\right.$-order in $10^{-4} *$ $\left.\mathrm{mg}^{1 / 2} .100 \mathrm{~mL}^{-1 / 2} \cdot \mathrm{min}^{-1}\right)$ and comparison between the calculated $n$-values for ascorbic acid degradation in anaerobic condition $(n=0.84)$ and in aerobic conditions $(n=0.44)$.

\begin{tabular}{lllll}
\hline Conditions & Temperature $\left({ }^{\circ} \mathrm{C}\right)$ & $k \pm \mathrm{SD}^{\mathrm{a}}$ & $R^{2}$ & $R^{2}$ for $n=0.84$ \\
\hline Anaerobic & 95 & $2.73 \pm 0.04$ & 0.996 & 0.996 \\
& 105 & $6.19 \pm 0.17$ & 0.999 & 0.999 \\
& 115 & $13.71 \pm 0.22$ & 0.999 & 0.999 \\
Aerobic & 125 & $28.75 \pm 0.61$ & 0.999 & 0.999 \\
& 95 & $552 \pm 30$ & 0.994 & - \\
& 105 & $604 \pm 0$ & 0.996 & 0.44 \\
& 115 & $599 \pm 39$ & 0.996 & 0.994 \\
& $418 \pm 3$ & 0.990 & 0.997 \\
\end{tabular}

\footnotetext{
${ }^{\text {a }} \mathrm{SD}=$ Standard deviation.
} 
canning temperatures, the aerobic mechanism is present and predominant. Though $\mathrm{O}_{2}$ saturation concentrations are low at elevated temperature, the model of Tromans (1998) for $\mathrm{O}_{2}$ solubility indicates about $16 \mathrm{mg} / \mathrm{L}$ at $0.3 \mathrm{MPa}$. This value was determined using the model established by Tromans and described by equation (8) (Tromans, 1998):
Oxygen is a major factor in ascorbic acid degradation. The significance of oxygen was significantly higher (2.5 times) than process temperature, as $50 \%$ degradation of ascorbic acid is observed after $240 \mathrm{~min}$ and $100 \mathrm{~min}$ thermal treatment at $125{ }^{\circ} \mathrm{C}$ in anaerobic and aerobic conditions, respectively. Furthermore, the thermal stability of ascorbic acid in anaerobic conditions is higher signifi-

$\left[O_{2}\right]=P_{02} * \exp \left(\frac{0.064 * T^{2}+203.357 * T * \ln \left(\frac{T}{298}\right)-(299.378+0.092 * T)(T-298)-20.591 * 10^{3}}{R^{*} T}\right)$

where $\left[\mathrm{O}_{2}\right]$ is the dissolved oxygen concentration in mol. $\mathrm{L}^{-1}$ and $\mathrm{P}_{\mathrm{O} 2}$ is the oxygen partial pressure in MPa.

In our experiment, the air pressure was set at $0.3 \mathrm{MPa}$, so the partial pressure of oxygen was $\mathrm{P}_{\mathrm{O} 2}=0.21 * 0.3 \mathrm{MPa}=0.063 \mathrm{MPa}$.

The values of dissolved oxygen concentration depending on temperature are reported in Table 2.

There is a non-negligible amount of dissolved oxygen in the heating media, which could explain the importance of the aerobic pathway compared to anaerobic pathway.

A second point was that the four curves were very similar, so the effect of temperature was very limited, while in anaerobic conditions a classical acceleration of degradation rate with temperature was recorded. As it can be hypothesized that this mechanism is still present, purely oxidative degradation would decrease with increasing temperature, which demands further investigation.

A last point is that ascorbic acid degradation did not follow firstorder kinetics, nor zero-order kinetics in these conditions.

An $n$-value of 0.44 was obtained by fitting the curves. Therefore, $n=0.5$ was used to fit the kinetics. To verify if this simplification is coherent, the $R^{2}$ was compared for $n=0.44$ and $n=0.5$. A good fit was obtained for all four temperatures using $n=0.5\left(R^{2}>0.99\right)$ and the $R^{2}$ was the same for the two different $n$-values (Table 1 ). The values of 0.5 -order kinetic constants are reported in Table 1.

The kinetic constant did not vary significantly with temperature and did not fit in Arrhenius plot (Fig. 3). It was impossible to determine an activation energy for aerobic ascorbic acid degradation during sterilization. In aerobic conditions at sterilization temperatures, there was an unidentified factor in ascorbic acid degradation.

\section{Conclusion}

Ascorbic acid degradation follows first-order kinetics at high temperatures $\left(>100^{\circ} \mathrm{C}\right)$ under anaerobic conditions but it follows 0.5 -order kinetics in aerobic conditions. In anaerobic conditions, the good fit of first-order kinetics confirmed that there was only one involved mechanism, the hydrolytic pathway, compared to aerobic conditions where two pathways at least are involved.

Table 2

Concentration of dissolved oxygen in the heating media depending on temperature, according to Tromans's model.

\begin{tabular}{ll}
\hline Temperature $\left({ }^{\circ} \mathrm{C}\right)$ & {$\left[\mathrm{O}_{2}\right]\left(\mathrm{mg} \mathrm{L}^{-1}\right)$} \\
\hline 95 & 15.5 \\
105 & 15.6 \\
115 & 15.9 \\
125 & 16.5 \\
\hline
\end{tabular}

cantly than known stability in aerobic. Indeed, under anaerobic conditions, 320 min treatment even at $125^{\circ} \mathrm{C}$ was not sufficient to degrade all the ascorbic acid initially present.

In aerobic conditions, oxygen availability may be reduced due to the high temperatures that may decrease its solubility, but it stays non negligible. Removing oxygen from the medium appeared to be the better solution to preserve the maximum of vitamins during heat drastic treatments, but it can be difficult to achieve in food industry (matrix complexity, needed of specific devices, etc ...).

\section{References}

Al-Zubaidy, M. M. I., \& Khalil, R. A. (2007). Kinetic and prediction studies of ascorbic acid degradation in normal and concentrate local lemon juice during storage. Food Chemistry, 101(1), 254-259.

Berlinet, C., Brat, P., Brillouet, J.-M., \& Ducruet, V. (2006). Ascorbic acid, aroma compounds, and browning of orange juices related to PET packaging materials and pH. Journal of the Science of Food and Agriculture, 86(13), 2206-2212.

Blasco, R., Esteve, M. J., Frígola, A., \& Rodrigo, C. (2004). Ascorbic acid degradation kinetics in mushrooms in a high-temperature short-time process controlled by a thermoresistometer. LWT - Food Science and Technology, 37(2), 171-175.

Bosch, V., Cilla, A., García-Llatas, G., Gilabert, V., Boix, R., \& Alegría, A. (2013). Kinetics of ascorbic acid degradation in fruit-based infant foods during storage. Journal of Food Engineering, 116(2), 298-303.

Condón, S., Arrizubieta, M. J., \& Sala, F. J. (1993). Microbial heat resistance determinations by the multipoint system with the thermoresistometer TR-SC Improvement of this methodology. Journal of Microbiological Methods, 18(4), 357-366.

Conesa, R., Andreu, S., Fernández, A., Esnoz, A., \& Palop, A. (2009). Nonisothermal heat resistance determinations with the thermoresistometer Mastia. Journal of Applied Microbiology, 117(2), 506-513.

Esteve, M. J., Frígola, A., Martorell, L., \& Rodrigo, C. (1998). Kinetics of ascorbic acid degradation in green Asparagus during heat processing. Journal of Food Protection, 61(11), 1518-1521.

Garza, S., Teixidó, J. A., Sanchis, V., Viñas, I., \& Condón, S. (1994). Heat resistance of Saccharomyces cerevisiae strains isolated from spoiled peach puree. Food Microbiology, 23(2), 209-213.

Hsu, H.-Y., Tsai, Y.-C., Fu, C.-C., \& Wu, J. S.-B. (2012). Degradation of ascorbic acid in ethanolic solutions. Journal of Agricultural and Food Chemistry, 60(42), 10696-10701.

Jaffe, G. M. (1984). Ascorbic acid. Encyclopedia of Chemical Technology, 24, 8-40.

Jiang, L., Zheng, H., \& Lu, H. (2014). Use of Linear and Weibull functions to model ascorbic acid degradation in Chinese Winter Jujube during postharvest storage in light and dark conditions. Journal of Food Processing and Preservation, 38(3), 856-863.

Lin, S. H., \& Agalloco, J. (1979). Degradation kinetics of ascorbic acid. Process Biochemistry, 14(9), 22-24.

Mcllvaine, T. C. (1921). A buffer solution for colorimetric comparison. Journal of Biological Chemistry, 49(1), 183-186.

Mercali, G. D., Jaeschke, D. P., Tessaro, I. C., \& Marczak, L. D. F. (2012). Study of vitamin $C$ degradation in acerola pulp during ohmic and conventional heat treatment. LWT - Food Science and Technology, 47(1), 91-95.

Mercali, G. D., Schwartz, S., Marczak, L. D. F., Tessaro, I. C., \& Sastry, S. (2014). Effect of the electric field frequency on ascorbic acid degradation during thermal treatment by ohmic heating. Journal of Agricultural and Food Chemistry, 62(25), 5865-5870.

Oey, I., Verlinde, P., Hendrickx, M., \& Van Loey, A. (2006). Temperature and pressure stability of L-ascorbic acid and/or [6s] 5-methyltetrahydrofolic acid: A kinetic study. European Food Research and Technology, 223(1), 71-77.

Palop, A., Marco, A., Raso, J., Sala, F. J., \& Condón, S. (1997). Survival of heated 
Version définitive du manuscrit publiée dans / Final version of the manuscript published in :

LWT - Food Science and Technology (2016), 6 p., DOI: 10.1016/lwt.2016.08.043

Journal homepage : http://www.elsevier.com/locate/lwt

Bacillus coagulans spores in a medium acidified with lactic or citric acid. International Journal of Food Microbiology, 38(1), 25-30.

Palop, A., Raso, J., Pagàn, R., Condón, S., \& Sala, F. J. (1999). Influence of pH on heat resistance of spores of Bacillus coagulans in buffer and homogenized foods. International Journal of Food Microbiology, 46(3), 243-249.

Palop, A., Sala, F. J., \& Condón, S. (1997). Occurrence of a highly heat-sensitive spore subpopulation of Bacillus coagulans STCC 4522 and its conversion to a more heat-stable form. Applied and Environmental Microbiology, 63(6), 2246-2251.

Peng, J., Mah, J.-H., Somavat, R., Mohamed, H., Sastry, S., \& Tang, J. (2012). Thermal inactivation kinetics of Bacillus coagulans spores in tomato juice. Journal of Food Protection, 75(7), 1236-1242.

Raso, J., Palop, A., Bayarte, M., Condón, S., \& Sala, F. J. (1995). Influence of sporulation temperature on the heat resistance of a strain of Bacillus licheniformis (Spanish Type Culture Collection 4523). Food Microbiology, 12, 357-361.

Sapei, L., \& Hwa, L. (2014). Study on the kinetics of vitamin C degradation in fresh strawberry juices. Procedia Chemistry, 9, 62-68.

Serpen, A., \& Gökmen, V. (2007). Reversible degradation kinetics of ascorbic acid under reducing and oxidizing conditions. Food Chemistry, 104(2), 721-725.

Soares, N. F. F., \& Hotchkiss, J. H. (1999). Comparative effects of De-aeration and package permeability on ascorbic acid loss in refrigerated orange juice. Packaging Technology and Science, 12(3), 111-118.

Torregrosa, F., Esteve, M. J., Frígola, A., \& Cortés, C. (2006). Ascorbic acid stability during refrigerated storage of orange-carrot juice treated by high pulsed electric field and comparison with pasteurized juice. Journal of Food Engineering, 73(4), 339-345.

Tromans, D. (1998). Temperature and pressure dependent solubility of oxygen in water: A thermodynamic analysis. Hydrometallurgy, 48(3), 327-342.

Van Boekel, M. A. J. S. (2009). Kinetic Modeling of Reactions in Foods. Boca Raton: Taylor \& Francis Group.

Van den Broeck, I., Ludikhuyze, L., Weemaes, C., Van Loey, A., \& Hendrickx, M. (1998). Kinetics for isobaric-isothermal degradation of L-ascorbic acid. Journal of Agricultural and Food Chemistry, 46(5), 2001-2006.

Yuan, J. P., \& Chen, F. (1998). Degradation of ascorbic acid in aqueous solution. Journal of Agricultural and Food Chemistry, 46(12), 5078-5082.

Zimmermann, M., Longhi, D. A., Schaffner, D. W., \& Aragão, G. M. F. (2014). Predicting Bacillus coagulans spores inactivation in tomato pulp under nonisothermal heat treatments. Journal of Food Science, 79(5), 935-940. 